\title{
The radiation therapy options of intracranial hemangiopericytoma: An overview and update on a rare vascular mesenchymal tumor
}

\author{
Maria Paola Ciliberti, Rosa D’Agostino, Laura Gabrieli, Anna Nikolaou, Angela Sardaro \\ Department of Interdisciplinary Medicine, Section of Diagnostic Imaging and Radiotherapy, University Aldo Moro, \\ Bari, Italy
}

\begin{abstract}
Hemangiopericytoma (HPC) is an extremely rare hypervascular tumor of mesenchymal lineage. It tends to recur and to develop distant metastases even many years after primary surgical resection. The management of recurrent and metastatic disease is not always so well defined. A complete surgical resection does not eliminate the high risk of local recurrences that occur in the central nervous system, often in the same surgical bed. However, treatment with adjuvant radiotherapy even in cases of complete resection remains controversial. Because of its rarity, there is no standard for treatment. We focused on radiotherapy treatment options, analyzing the literature and making a base on conduct further studies to establish the standard radiation dose to be used for locoregional control of such a complex and extremely rare disease and to help specialists to take the most appropriate therapeutic option.
\end{abstract}

\section{Introduction}

Hemangiopericytoma (HPC) is an extremely rare hypervascular tumor of mesenchymal lineage that arises from Zimmerman pericytes, the contractile cells surrounding vasculature around capillaries and post-capillary venules. HPC was first described by Stout and Murray in $1942^{1}$ and it may occur anywhere in the human body because of the ubiquity of blood vessels, involving primarily the soft tissues of the limbs or the retroperitoneal and retropleural spaces, but also the larynx, the bones, the spleen or the central nervous system (BIBLIO). Intracranial HPCs mostly arise from the meninges of the brain and spinal cord ${ }^{2}$. They con-

\footnotetext{
Correspondence: Laura Gabrieli, Strada vicinale Montenegro 6, 72100 Brindisi, Italy.

Tel.: +39.3492954929

E-mail: gabrielilaura@gmail.com

Key words: Hemangiopericytoma; radiotherapy; bone metastases; vascular tumor; mesenchymal tumor.

Received for publication: 12 January 2018

Accepted for publication: 20 June 2018.

This work is licensed under a Creative Commons Attribution NonCommercial 4.0 License (CC BY-NC 4.0).

CCopyright M.P,Ciliberti et al., 2018

Licensee PAGEPress, Italy

Oncology Reviews 2018; 12:354

doi:10.4081/oncol.2018.354
}

stitute less than $1 \%$ of all CNS tumors and $<2.5 \%$ of all meningeal tumor $^{1}$. The first reported case of hemangiopericytoma originating in the meninges was described by Begg and Garret in $1954 .^{3}$ Meningeal HCP were originally considered a variation of meningioma, and they were called "angioblastic meningiomas". The inclusion of CNS HPCs as a distinct entity in the CNS tumors classification has been a matter of debate for many years until the World Health Organization distinguished them from meningiomas in 1993 classifying HPCs into the group of "mesenchymal, nonmeningothelial tumors"4 thanks to its special clinical behavior, together with its immunohistochemical, structural and genetic characteristics. ${ }^{5,6,7,8,9}$ In the general pathology community, HPC is considered part of a spectrum with solitary fibrous tumor (SFT), with HPC representing a more biologically aggressive form. This classification approach has not yet been embraced by neuropathologists and is still under debate. The most recent World Health Organization (WHO) classification of the tumors of soft tissue considered the term HPC obsolete, and places all such tumors within the extrapleural SFT category. In contrast, CNS SFT and HPC continue to be regarded as different entities in the latest version of the WHO CNS tumor classification. A change in this approach is currently being considered for the upcoming revision of the WHO scheme. Now, these lesions are classified as World Health Organization (WHO) grade II (HPC) or WHO grade III (anaplastic HPC) lesions. Anaplastic HPC has a higher recurrence rate and the tendency to metastasize outside the CNS, typically to the liver, lungs, and bones, necessitating long-term close clinical and radiologic follow-up.

Because of its rarity, there is no standard for treatment. We focused on radiotherapy treatment options, analyzing the literature and making a base on conduct further studies to establish the standard radiation dose to be used for locoregional control of such a complex and extremely rare disease and to help specialists to take the most appropriate therapeutic option.

\section{Epidemiology}

Most HPCs occur in adults, with a median age of 45-50 years. HPCs reportedly have a slightly higher preponderance among male individuals, and patients most often present with headaches. The majority of reported HPCs were supratentorial, but the tumors were found anywhere along the neuraxis.

\section{Ethiopathogenesis}

The etiology of HPC is still a dilemma. When a hemangiopericytoma develops in a child, it is sometimes considered congenital. In some families, several members of a generation all have tumors. There could be a link between Hemangiopericytoma 
development and a tendency to develop other tumors.

Multiple research groups successfully detected the specific gene fusion NAB2-STAT6 in both soft tissue SFT and HPC specimens. The fusion gene products promote tumor cell proliferation by activating the early growth response (EGR) gene and play an important role in HPC tumorigenesis.

\section{Clinical aspects}

The symptoms of this type of tumor are non-specific and often similar to those of other types of tumors, such as meningeal meningoma and they depend on the tumor size, extent, involvement of surrounding structures and position. Intracranial HCPs symptoms could be headache, dizziness, vomiting, weakness and blurred vision. Additional presenting symptoms included papilledema, hemiparesis, gait disturbance, and ataxia, depending on the localization of the tumor. Due to the intense vascularity, to the erosion, distorsion or distension of great vessels and endothelial proliferation, MHCPs can also present as acute intracranial hemorrage ${ }^{10}$ carrying the risk of life threatening massive bleeding. ${ }^{11}$

\section{Diagnostic tools}

Routine laboratory tests are not specific. ${ }^{12}$

Intracranial HPCs can show very similar features to meningioma on both CT and MRI. They often presents as an extraaxial, multilobulated mass. They can have a narrow or a broad base of dural attachment. Unlike meningiomas, which frequently show hyperostosis of adjacent bone and may have intratumoral calcifications on unenhanced CT scans, HPCs show bone erosion and lack calcifications and hyperostosis. Unenhanced CT scans of hemangiopericytomas typically show hyperdense heterogeneous tumors, and T1-weighted and T2-weighted MR images typically show heterogeneous isointense tumors. On contrast-enhanced CT scans and MR images, HCPs show an heterogeneous enhancement. ${ }^{13} \mathrm{HCPs}$ also shows marked vascularity similar to meningioma on angiography. A recent retrospective analysis concluded that tumors presenting outside the brain parenchyma, with isointense to slightly intense regions on MRI scans, oval/lobular shape, well- or illdefined margins, signal-void vessels, apparent cystic areas, dual blood supply, and intense enhancement on CT or MRI scans, but without calcification or a "dural tail" sign, may be diagnosed as HPCs. ${ }^{14}$ PET-CT could be useful in differentiating the two entities, showing avid enhancement on CT but low FDG uptake on PET, indicative of low glucose utilisation. ${ }^{15}$ Some investigators have reported also the potential role of multitracers (F-FDG, Cmethionine, and O-H2O) PET imaging or dual-tracer (C-acetate and F-FDG) PET/CT imaging or 111In-pentetreotide scan in distinguishing intracranial HPC from meningioma. ${ }^{16,17}$ PET-CT is useful in the diagnostic pathway both to distinguish HCP from meningiomas but also to find distant metastases undetected by simple CT.

Immuno-histochemical study in addition to routine histopathological examination is essential to differentiate intracranial HPCs from angiomatous/anaplastic meningiomas and solitary fibrous tumor. ${ }^{18}$ Compared with MNG, MHPCs showed strong vimentine (100\% of cases), CD99 (62\%), bcl-2 (87\%), and p16 (75\%) staining but only focal positivity with EMA (33\%) and NSE (37\%). ${ }^{19}$

\section{Radiation therapy options}

The treatment for intracranial hemangiopericytomas is primarily total surgical resection of the lesion whenever possible. It correlates with the free interval of recurrence and overall survival. ${ }^{20,21,22,23}$ Pre-surgical embolization should be considered to reduce the risk of bleeding heavily during operation. ${ }^{24,25}$ Neoadjuvant radiotherapy has been also advocated to reduce intraoperative complications. ${ }^{26,27,28}$

However, a complete surgical resection does not eliminate the high risk of local recurrences that occur in the central nervous system, often in the same surgical bed. The extension of surgical resection is very important: a large series has demonstrated a survival ratio of 10 years through $69 \%$ of those who underwent a gross total resection, compared to $44 \%$ of those who obtained a subtotal resection. ${ }^{7}$ The high propensity to local recurrence suggests a role for postoperative Radiotherapy. Sheehan et al. reported a decrease in local recurrences from $88 \%$ with surgery alone to $12.5 \%$ with surgery and postoperative RT. ${ }^{42}$ Recently, Kim et al. performed adjuvant RT (50 to $60 \mathrm{~Gy}$ ) regardless of the extent of resection and pathologic grade in most of the patients and showed that the patients who received adjuvant RT tend to have longer RFS without significant radiation-related complications. ${ }^{29}$ However, treatment with adjuvant radiotherapy even in cases of complete resection remains controversial. Many data have been published, but they often originate in small samples of retrospective studies and have conflicting results. Some studies found a improved recurrence-free survival with post-operative $\mathrm{RT}^{9,30,31,32,33}$ allowing protection also against tumor metastasis in neuraxis via cerebrospinal fluid but without impact on extra-CNS distant metastases. A recent review over 52 patients showed that postoperative RT significantly lengthened both local control (5 year LC rates of 97 vs 44\%) and overall survival (10 year OS rates of 83 and $25 \%$ ) independent of the extent of resection, without a preventive effects on regional and distant metastases. The main patterns of failure were local recurrence in patients who did not receive PORT and distant metastasis in those who received PORT. ${ }^{34}$ Other studies showed no benefit in the addition of radiotherapy after a total resection when compared to gross total resection alone, and total dose $>50$ Gy was associated with increased mortality rates; postoperative radiotherapy offered no survival benefit also in cases of subtotal resection. ${ }^{20} \mathrm{~A}$ recent retrospective review of 43 cases showed that postoperative radiation therapy may be able to prolong the time before first recurrence $(p=0.04)$, but it does not confers a survival benefit $(p=0.2) .{ }^{35}$ The most common dose of postoperative RT is $45-50 \mathrm{~Gy} .{ }^{36,37}$ In case of residual or recurrent small-sized meningeal HPC, radiotherapy and in particular steretactic radiosurgery (SRS) seems to be an effective treatment with excellent results. An analysis of high-precision RT (SRS or fractionated IMRT for more complex targets) for patients with intracranial HCPs demonstrates that high overall survival rates $(100 \%$ and $64 \%$ at 5 and 10 years, respectively) can be obtained in patients by combining surgical and RT approaches. The main advantage of high-precision RT is the possibility of delivering high doses to more complex target volumes and sparing organs at risk, helping to improve local tumor control and preserving the patient's quality of life. ${ }^{38}$ Also Gamma Knife radiosurgery is a feasible and effective therapy in the management of HPCs. ${ }^{39}$ Meningeal HPCs can recur locally or distantly in the neural axis or as distant extraneural metastases. The recurrence and metastasis rates of intracranial HPC were reported to be $80 \%$ and $23 \%$, respectively, and the 5-year metastasis rate is approximately $33 \% .{ }^{40}$ The incidence of extraneural metastases of M-HPC ranges from $12 \%{ }^{1}$ to $57 \%{ }^{41}$ Metastases occurred 2- 20 years after the initial 
Table 1. Papers reporting cases of intracranial HPC that developed bone metastases.

\begin{tabular}{|c|c|c|c|c|c|c|}
\hline Author & $\mathrm{N}$ pts & $\begin{array}{c}\text { Metastases } \\
(\%)\end{array}$ & $\begin{array}{c}\text { Site } \\
\text { of metastases }\end{array}$ & $\begin{array}{l}\text { Time to met } \\
\text { (median) }\end{array}$ & Treatment of bone & $\begin{array}{l}\text { Outcome } \\
\text { metastases }\end{array}$ \\
\hline $\begin{array}{l}\text { Goellner, } 1978 \\
\text { Anderson, } 1980\end{array}$ & $\begin{array}{c}26 \\
1\end{array}$ & $\begin{array}{c}23 \\
100\end{array}$ & $\begin{array}{c}\text { Retroperitoneum, liver, lung, bones } \\
\text { Bones }\end{array}$ & $\begin{array}{l}8.6 \mathrm{yrs} \\
5 \mathrm{yrs}\end{array}$ & $\begin{array}{c}\text { Unavailable } \\
\text { Surgery + RT (femur) } \\
\text { RT } \\
\text { CHT }\end{array}$ & $\begin{array}{c}\text { Unavailable } \\
\text { Slowly progressive } \\
\text { disease at } 3 \text { yrs }\end{array}$ \\
\hline Jaaskelainen, 1985 & 21 & 14 & $\begin{array}{l}\text { Bones, liver, pleura, } \\
\text { lung, subcutis }\end{array}$ & $6,4 \mathrm{yrs}$ & Unavailable & $\begin{array}{c}\text { Slowly progressive } \\
\text { disease at } 6,5 \text { yrs }\end{array}$ \\
\hline Staples, 1990 & 15 & 53 & $\begin{array}{l}\text { Bones, lung, subcutaneous tissue, } \\
\text { massive intraddominal disease }\end{array}$ & 3 yrs & RT (26-30 Gy, 10-13 fr) & NED after 11 yrs \\
\hline Sakata, 1998 & 1 & 100 & Bones & $\begin{array}{l}20 \text { yrs after } \\
\text { the first } \\
\text { treatment }\end{array}$ & $\begin{array}{c}\text { RT (60 Gy in } 24 \text { fr over } \\
5 \text { weeks, } 39 \text { Gy } \\
\text { in } 13 \text { fr over } 3 \text { weeks, } \\
20 \text { Gy in } 4 \text { fr over } 2 \text { weeks) + } \\
\text { CHT }\end{array}$ & $\begin{array}{l}\text { Partial response } \\
\text { and no regrowth; } \\
\text { good palliation }\end{array}$ \\
\hline Dufour, 2001 & 21 & 19 & Bones, lung & $12 \mathrm{yrs}$ & Unavailable & $\begin{array}{l}\text { Slowly progressive } \\
\text { disease at } 4 \text { yrs }\end{array}$ \\
\hline Someya, 2001 & 4 & 50 & Bones liver, lung, brain & $7.5 \mathrm{yrs}$ & $\begin{array}{l}\text { RT bone } 1: 25 \mathrm{~Gy} \text { in } 5 \mathrm{fr} \text {, } \\
50 \mathrm{~Gy} \text { in } 16 \mathrm{fr} \\
\mathrm{S} \rightarrow \text { RT: } 37.5 \mathrm{~Gy} \text { in } 15 \mathrm{fr} \\
\text { RT bone } 2: 25 \mathrm{~Gy} \text { in } 5 \mathrm{fr} \\
\text { RT bone } 3: 35 \mathrm{~Gy} \text { in } 8 \mathrm{fr}\end{array}$ & Death after 9 years \\
\hline Suzuki, 2002 & 1 & 100 & Pancreas, bones & $22 \mathrm{yrs}$ & RT & SD at $2 \mathrm{yrs}$ \\
\hline Ecker, 2003 & 38 & 29 & $\begin{array}{l}\text { Spine, chest wall, } \\
\text { liver, pelvis, lungs, } \\
\text { orbit, femur, deltoid, } \\
\text { breast, humerus }\end{array}$ & Unavailable & $\begin{array}{c}\text { Radiosurgical tratment } \\
\text { and salvage chemotherapy } \\
\text { treatment }\end{array}$ & $\begin{array}{l}5 \text { yrs survival } \\
\text { rate } 93 \%\end{array}$ \\
\hline $\begin{array}{l}\text { Kim, } 2003 \\
\text { Souyer, } 2004\end{array}$ & $\begin{array}{l}31 \\
29\end{array}$ & $\begin{array}{l}12.9 \\
55\end{array}$ & $\begin{array}{l}\text { Liver, lung bones } \\
\text { Lung, bone, liver, spinal }\end{array}$ & $\begin{array}{l}8.9 \text { yrs } \\
97 \text { months }\end{array}$ & $\begin{array}{c}\text { Unavailable } \\
\text { Gross total resection } \\
\text { or subtotal resection + } \\
\text { or - RT }\end{array}$ & $\begin{array}{l}\text { Unavailable } \\
\text { The } 5,10 \text { and } \\
\text { 15-year overall } \\
\text { survival rates } 85 \% \text {, } \\
68 \% \text { and } 22 \%\end{array}$ \\
\hline Pistolesi, 2004 & 1 & 100 & Bones, Adrenal glands & $12 \mathrm{yrs}$ & $\begin{array}{c}\text { Surgery (femur) } \\
\text { RT (30 Gy in } 10 \text { fractions) } \\
\text { (vertebra) }\end{array}$ & NR \\
\hline Chang, 2004 & 1 & 100 & Bones, liver & 5 yrs & RT 43.2 Gy & PD at $1 \mathrm{yr}$ \\
\hline Hoshi, 2005 & 15 & 100 & Bones & $>10 \mathrm{yrs}$ & RT, S & Unavailable \\
\hline Fountas, 2006 & 11 & 36.4 & Bones, liver, lung & $4.9 \mathrm{yrs}$ & Unavailable & All dead \\
\hline Purandare, 2010 & 1 & 100 & Bones & 8 yrs & RT (dse not specified) & SD at few months \\
\hline Bassiouni, 2007 & 12 & 17 & Unavailable & Unavailable & Unavailable & Unavailable \\
\hline Ywamuro, 2008 & 1 & 100 & Bones, liver & 9 yrs & S & SD at 5 years \\
\hline Ambrosini- Spaltro, 20 & 0101 & 100 & Hip & $13 \mathrm{yrs}$ & Unavailable & Unavailable \\
\hline Schiariti, 2011 & 39 & 26 & $\begin{array}{l}\text { Lung, bones, liver, } \\
\text { muscle }\end{array}$ & $\begin{array}{l}75 \text { months after } \\
\text { their initial surgery }\end{array}$ & $\begin{array}{l}\text { Surgical excision and } \\
\text { EBRT when radical } \\
\text { excision no possible and/ } \\
\text { or chemotherapy }\end{array}$ & $\begin{array}{c}\text { Overall survival rates at } 5 \text {, } \\
0,15 \text {, and } 20 \text { yrs } 93 \% \text {, } \\
167 \%, 45 \% \text { and } 23 \%\end{array}$ \\
\hline Rutkoski, 2012 & 35 & 20 & Liver, skin, bone lung & Unavailable & Unavailable & $4 / 7$ died \\
\hline Siegel, 2012 & 1 & 100 & Bones & $13 \mathrm{yrs}$ & $\mathrm{S}$ (wide resection) & NED at 7 yrs \\
\hline Kumar, 2012 & 15 & 7 & Bones & 5 yrs & RT (dose not specified) & Unavailable \\
\hline Ghia, 2013 & 63 & 33 & Unavailable & $10 \mathrm{yrs}$ & RT & Unavailable \\
\hline Stessin, 2013 & 76 & Unavailable & Unavailable & Unavailable & $\begin{array}{c}\text { Total resection } \\
\text { or Subtotalresection + RT }\end{array}$ & Unavailable \\
\hline Satayasoontorn, 2014 & 4 & 100 & Bones & $7 \mathrm{yrs}$ & Unavailable & Unavailable \\
\hline Manatakis, 2015 & 1 & 100 & Bone, liver & $12 \mathrm{yrs}$ & SRS & Unavailable \\
\hline Nakada, 2015 & 2 & 100 & Bones & $8 \mathrm{yrs}$ & Unavailable & Unavailable \\
\hline $\begin{array}{l}\text { Yamazaky, } 2016 \\
\text { months }\end{array}$ & 1 & 100 & Rib & $2 \mathrm{yrs}$ & S & $\begin{array}{c}\text { PD (multiple bone met) } \\
\text { after } 6\end{array}$ \\
\hline Wei, 2015 & 1 & 100 & Bones, kidneys & $4 \mathrm{yrs}$ & $\begin{array}{l}\text { C (bevacizumab + } \\
\text { temozolomide })+ \\
\text { RT ( } 40 \text { Gy in } 10 \text { fr })\end{array}$ & Stable disease \\
\hline
\end{tabular}


diagnosis, and the average time-to-metastasis varied from 63 to 99 months. ${ }^{42}$ A systematic review over 523 patients showed a median time-to.metastasis of 91 months after primary surgical resection. ${ }^{43}$ Galanis et al. ${ }^{40}$ noted that bone and liver were the most common metastatic sites $(82 \%$ and $41 \%$ of extraneural recurrences, respectively), while Brunori et al. ${ }^{44}$ reported that the preferential sites were lung, bone, soft tissue, and liver. In a review of 94 cases published in 1991, the most common sites of metastases have been bone, lung, abdominal cavity, lymph nodes, skeletal muscle, kidney, pancreas and skin. ${ }^{7}$ A series of risk factors relevant to hematogenous dissemination capacity have been postulated, including subtotal resection of the tumor, development of local recurrence, large tumor size, and the tumor site (ex. proximity to venous sinuses). ${ }^{45}$ Local or distant recurrence is often a late event, ${ }^{46}$ and the probability of developing distant metastases increases steadily with time. ${ }^{47} \mathrm{Kim}$ et al. showed that extraneural metastases developed at an average of 107 months after the first operation, with 5- and 10-year metastasis rates of $4.4 \%$ and $24.9 \%$, respectively. ${ }^{48}$ Brunori et al. ${ }^{44}$ reported that the mean interval to first recurrence was 84 months, Guthrie et al. ${ }^{21}$ and Goellner et $a l .{ }^{49}$ showed the recurrence rate at 10 years and 15 years after surgery, respectively, was $76 \%$. In the series reported by Kim et al. ${ }^{48}$ the overall average period before the first recurrence was 104 months. All these studies suggest the need of a close follow-up for a long period after the first surgical removal, that should include complete physical examination, chest X-rays, abdominal ultrasound, and total body CT or PET/TC, when indicated.

Table 1 reports a series of papers reporting cases of intracranial HPC that developed bone metastases. The median time-to-metastases was 8 years (range 2-22 yrs). Bone metastases were treated with surgery, chemotherapy or palliative Radiotherapy or a combination of treatment modality. RT doses are not always reported: they ranged from 25 to $50 \mathrm{~Gy}$, given often with a hypofractionated modality. A strategy of optimal systemic treatment of metastatic HPC has not yet been identified, being the role of anthracyclinesbased chemotherapy still controversial due to its modest efficacy in this setting of patients. ${ }^{50,51}$ The recent identifiction of the fusion gene NAB2-STAT6 both in HPC and in solitary fibrous tumors ${ }^{52,53}$ shows a new area of research. The overexpression of the Vascular Endothelial Growth Factor Receptor (VEGFR) and PlateletDerived Growth Factor Receptor (PDGFR) encourages the study of targeted therapies with antiangiogenic drugs. ${ }^{54,55,56,57,58}$ Park et al. analyzed the records of 14 patients with HPC/SFT treated with temozolomide and bevacizumab: $79 \%$ of patients achieved a partial response, $14 \%$ had stable disease only 1 patient had progressive disease, concluding that this generally well-tolerated combination therapy is clinically beneficial. ${ }^{51}$ Despite the tumor's natural tendency to recur and metastatize outside the CNS, it is possible to ensure a long survival time and a good quality of life. Palliative radiation of painful bone lesions has been reported to control pain successfully. Doses of $30 \mathrm{~Gy} / 10$ fractions. The long-term benefit of wide resection of a solitary metastatic bone lesion is not well known. Staples et al. showed that pain due to bone metastases was palliated by 12 Gy in 4 fractions and 30 Gy in 15 fractions. ${ }^{59}$ Friedmand and Egan reccomend a dose up to 30 Gy over 18 days, ${ }^{60}$ while Sakata et al. reported both a pain relief and a prevention of pathological fractures with doses up to 20-60 Gy in 4-24 fractions. ${ }^{61}$ Palliative therapy with irradiation of bone metastases could provide good local control and mantain the patients' quality of life.

\section{Conclusions}

RT seems to carve out a significant role in the treatment of such a complex and extremely rare disease.

The available literature reveals no consensus about the radiation dose to be used for the locoregional control of HPC. Treatment with adjuvant radiotherapy even in cases of complete resection remains controversial. Many data have been published, but they often originate in small samples of retrospective studies and have conflicting results. So, further studies are needed.

Our experience confirms data of literature: even after gross total resection, we observed a long time-to-metastases (5 years) and an overall mean survival of 8 years. Palliative RT conducted with 30 Gy in 10 fractions over two weeks was effective both in slowing down disease progression and in giving pain relief of the metastatic bone allowing a good quality of life. Actually, no doubt evidence is all in favor of RT obtaining local pain control with good tolerance and better quality of life at least at one-year-follow up.

\section{References}

1. Stout AP, Murray MR. Hemangiopericytoma: a vascular tumor featuring Zimmermann's pericytes. Ann Surg 1942;116:26-33.

2. D'Amore ES, Manivel JC, Sung JH. Soft-tissue and meningeal hemangiopericytomas: an immunoh- istochemical and ultrastructural study. Hum Pathol 1990;21:414-23.

3. Begg CF, Garret R. Hemangiopericytoma occurring in the meninges: case report. Cancer 1954;7:602-6.

4. Kleihues P, Burger PC, Scheithauer BW. The New WHO Classification of Brain Tumours. Brain Pathol 1993;3:255-68.

5. Coffey RJ, Cascino TL, Shaw EG. Radiosurgical treatment of recurrent hemangiopericytomas of the meninges: preliminary results. J Neurosurg 1993;78:903-8.

6. Joseph JT, Lisle DK, Jacoby LB, et al. NF2 gene analysis distinguishes hemangiopericytoma from meningioma. Am J Pathol 1995; 147:1450-5.

7. Mena H, Ribas JL, Pezeshkpour GH, et al. Hemangiopericytoma of the central nervous system: a review of 94 cases. Hum Pathol 1991;22:84-91.

8. Ramsey HJ. Fine structure of hemangiopericytoma and hemangio-endothelioma. Cancer 1966;19:2005-18.

9. Schiariti M, Goetz P, El-Maghraby $H$, et al. Hemangiopericytoma: long-term outcome revisited. Clinical article. J Neurosurg 2011;114:747-55.

10. Maruya J, Seki Y, Morita K, et al. Meningeal hemangiopericytoma manifesting as massive intracranial hemorrhage--two case reports. Neurol Med Chir (Tokyo) 2006;46:92-7.

11. Tanaka T, Kato N, Hasegawa Y, Murayama Y. Unpredicted Sudden Death due to Recurrent Infratentorial Hemangiopericytoma Presenting as Massive Intratumoral Hemorrhage: A Case Report and Review of the Literature. Case Rep Neurol Med 2014;2014:230681.

12. Ma C, Xu F, Xiao YD, et al. Magnetic resonance imaging of intracranial hemangiopericytoma and correlation with pathological findings. Oncol Lett 2014;8:2140-4.

13. Chiechi MV, Smirniotopoulos JG, Mena H. Intracranial hemangiopericytoma: MR and CT features. Am J Neuroradiol 1996;17:1365-71.

14. Pang H, Yao Z, Ren Y, et al. Morphologic patterns and imaging features of intracranial hemangiopericytomas: a retrospective analysis. Onco Targets Ther 2015 20;8:2169-78.

15. Chan WS, Zhang J, Khong PL, et al. 18F-FDG-PET-CT imaging findings of recurrent intracranial haemangiopericytoma with distant metastases. Br J Radiol 2010;83:e172-4.

16. Jong I, Chen S, Leung YL, et al. C-acetate PET/CT in a case of recurrent hemangiopericytoma. Clin Nucl Med 
2014;39:478-9.

17. Kota G, Gupta P, Lesser GJ, et al. Somatostatin receptor molecular imaging for metastatic intracranial hemangiopericytoma. Clin Nucl Med 2013;38:984-7.

18. Abdollahi A, Abdollahpouri R, Tavangar SM. Meningeal Hemangiopericytoma in 33-Year-Old Female; a Case Report. Iran J Pathol 2016;11:281-5.

19. Trabelsi S, Mama N, Chourabi M, et al. Meningeal Hemangiopericytomas and Meningomas: a Comparative Immunohistochemical and Genetic Study. Asian Pac J Cancer Prev 2015;16:6871-6.

20. Rutkowski MJ, Jian BJ, Bloch O, et al. Intracranial hemangiopericytoma: clinical experience and treatment considerations in a modern series of 40 adult patients. Cancer 2012;118:1628-36.

21. Guthrie BL, Ebersold MJ, Scheithauer BW, Shaw EG. Meningeal hemangiopericytoma: histopathological features, treatment, and long-term follow-up of 44 cases. Neurosurgery 1989;25:514-22.

22. Jaaskelainen J, Servo A, Halta M, et al. Intracranial hemangiopericytoma: radiology, surgery, radiotherapy, and outcome in 21 patients. Surg Neurol 1985;23:227-36.

23. Suzuki H, Haga Y, Oguro K, et al. Intracranial hemangiopericytoma with extracranial metastasis occurring after 22 years. Neurol Med Chir (Tokyo) 2002;42:297-300.

24. Fusco MR, Salem MM, Gross BA, et al. Preoperative Embolization of Extra-axial Hypervascular Tumors with Onyx. J Cerebrovasc Endovasc Neurosurg 2016;18:12-8.

25. Schmalbach CE, Gourin C. Managing Vascular Tumors-Open Approaches. Otolaryngol Clin North Am 2016;49:777-90.

26. Someya M, Sakata KL, Oouchi A, et al. Four cases of meningeal hemangiopericytoma treated with surgery and radiotherapy. Jpn J Clin Oncol 2001;31:548-52.

27. Carella RJ, Ransohoff J, Newall J. Role of radiation therapy in the management of meningioma. Neurosurgery 1982;10:3329.

28. Uemura S, Kuratsu J, Hamada J, et al. Effect of radiation therapy against intracranial hemangiopericytoma. Neurol Med Chir (Tokyo) 1992;32:328-32.

29. Kim YJ, Park JH, Kim YI, Jeun SS. Treatment Strategy of Intracranial Hemangiopericytoma. Brain Tumor Res Treat 2015;3:68-74.

30. Alén JF, Lobato RD, Gómez PA, et al. Intracranial hemangiopericytoma: study of 12 cases. Acta Neurochir (Wien) 2001;143:575-86.

31. Boto GR, Lagares A, Ramos A, et al. Intracranial Hemangiopericytomas: A Retrospective Study of 15 Patients with a Special Review of Recurrence. J Korean Neurosurg Soc 2015;58:211-6.

32. Lal H, Sanyal B, Pant GC, et al. Hemangiopericytoma: report of three cases regarding role of radiation therapy. AJR Am J Roentgenol 1976;126:887-91.

33. Park B-J, Kim Y-I, Hong Y-K, et al. Clinical Analysis of Intracranial Hemangiopericytoma. J Korean Neurosurg Soc 2013;54:309-16.

34. Lee EJ, Kim JH, Park ES, et al. The impact of postoperative radiation therapy on patterns of failure and survival improvement in patients with intracranial hemangiopericytoma. J Neurooncol. 2016;127:181-90.

35. Melone AG, D'Elia A, Santoro F, et al. Intracranial hemangiopericytoma--our experience in 30 years: a series of 43 cases and review of the literature. World Neurosurg 2014;81:556-62.

36. Dufour H, Metellus P, Fuentes S, et al. Meningeal hemangiopericytoma: a retrospective study of 21 patients with special review of postoperative external radiotherapy. Neurosurgery 2001;48:756-63.

37. Fountas KN, Kapsalaki E, Kassam M, et al. Management of intracranial meningeal hemangiopericytomas: outcome and experience. Neurosurg Rev 2006;29:145-53.

38. Combs SE, Thilmann C, Debus J, Schulz-Ertner D. Precision radiotherapy for hemangiopericytomas of the central nervous system. Cancer 2005;104:2457-65.

39. Spina A, Boari N, Gagliardi F, et al. The current role of Gamma Knife radiosurgery in the management of intracranial haemangiopericytoma. Acta Neurochir (Wien) 2016;158:63542.

40. Galanis E, Buckner JC, Scheithauer BW, et al. Management of recurrent meningeal hemangiopericytoma. Cancer 1998;82:1915-20.

41. Adegbite AB, Khan MI. The recurrence of intracranial meningiomas after surgical treatment. J Neurosurg 1983;58:51-6.

42. Sheehan J, Kondziolka D, Flickinger J, Lunsford LD. Radiosurgery for treatment of recurrent intracranial hemangiopericytomas. Neurosurgery 2002;51:905-11.

43. Ghose A, Guha G, Kundu R, et al. CNS Hemangiopericytoma: A Systematic Review of 523 Patients. Am J Clin Oncol 2014 [Epub ahead of print].

44. Brunori A, Delitala A, Oddi G, Chiappetta F. Recent experience in the management of meningeal hemangiopericytomas. Tumori 1997;83:856-61.

45. Cao Y, Zhang MZ, Wang JM, et al. Recurrent intracranial hemangiopericytoma with multiple metastases. Chin Med J (Engl) 2006;119:169-73.

46. Bastin KT, Mehta MP. Meningeal hemangiopericytoma: defining the role for radiation therapy. J Neurooncol 1992;14:27787.

47. Koyama H, Harada A, Nakao A, et al. Intracranial hemangiopericytoma with metastasis to the pancreas. Case report and literature review. J Clin Gastroenterol 1997;25:706-8.

48. Kim JH, Jung HW, Kim YS, et al. Meningeal hemangiopericytomas: long-term outcome and biological behavior. Surg Neurol 2003;59:47-53; discussion 53-4.

49. Goellner JR, Laws ER Jr, Soule EH, Okazaki H. Hemangiopericytoma of the meninges. Mayo Clinic Experience. Am J Clin Pathol 1978;70:375-80.

50. Beadle GF, Hillcoat BL. Treatment of advanced malignant hemangiopericytoma with combination adriamycin and DTIC: a report of four cases. J Surg Oncol 1983;22:167-70.

51. Park MS, Patel SR, Ludwig JA, et al. Activity of temozolomide and bevacizumab in the treatment of locally advanced, recurrent, and metastatic hemangiopericytoma and malignant solitary fibrous tumor. Cancer 2011;117:4939-47.

52. Trabelsi S, Mama N, Chourabi M, et al. Meningeal Hemangiopericytomas and Meningomas: a Comparative Immunohistochemical and Genetic Study. Asian Pac J Cancer Prev 2015;16:6871-6.

53. Schweizer L, Koelsche C, Sahm F, et al. Meningeal hemangiopericytoma and solitary fibrous tumors carry the NAB2STAT6 fusion and can be diagnosed by nuclear expression of STAT6 protein. Acta Neuropathol 2013;125:651-8.

54. Delgado M, Pérez-Ruiz E, Alcalde J, et al. Anti-angiogenic treatment (sunitinib) for disseminated malignant haemangiopericytoma: a case study and review of the literature. Case Rep Oncol 2011;4:55-9.

55. Kirn DH, Kramer A. Long-term freedom from disease progression with interferon alfa therapy in two patients with malignant hemangiopericytoma. J Natl Cancer Inst 1996;88:764-5.

56. Domont J, Massard C, Lassau N, et al. Hemangiopericytoma 
and antiangiogenic therapy: clinical benefit of antiangiogenic therapy (sorafenib and sunitinib) in relapsed malignant haeman-gioperyctoma/solitary fibrous tumour. Invest New Drugs 2010;28:199-202.

57. Rossi G, Schirosi L, Giovanardi F, et al. Pleural malignant solitary fibrous tumor with sarcomatous overgrowth showing PDGFRbeta mutation. Chest 2006;130:581-3.

58. De Pas T, Toffalorio F, Colombo P, et al. Brief report: activity of imatinib in a patient with platelet-derived-growth-factor receptor positive malignant solitary fibrous tumor of the pleu- ra. J Thorac Oncol 2008;3:938-41.

59. Staples JJ, Robinson RA, Wen BC, Hussey DH. Hemangiopericytoma--the role of radiotherapy. Int J Radiat Oncol Biol Phys 1990;19:445-51.

60. Friedman M, Egan JW. Irradiation of hemangiopericytoma of Stout. Radiology 1960;74:721-30.

61. Sakata K, Aoki Y, Tago M, et al. Radiotherapy of bone metastases of a spinal meningeal hemangiopericytoma. Strahlenther Onkol 1998;174:217-9. 